\title{
The role of mitochondrial DNA alterations in esophageal squamous cell carcinomas
}

\author{
Chen-Sung Lin, MD, ${ }^{\text {a,d,e }}$ Shi-Chuan Chang, MD, PhD, ${ }^{\text {a,b,f }}$ Liang-Shun Wang, MD, ${ }^{\text {a,b,h }}$ \\ Teh-Ying Chou, MD, PhD, ${ }^{\mathrm{a}, \mathrm{g}}$ Wen-Hu Hsu, MD, ${ }^{\mathrm{a}, \mathrm{e}}$ Yu-Chung Wu, MD, ${ }^{\mathrm{a}, \mathrm{e}}$ and Yau-Huei Wei, $\mathrm{PhD}^{\mathrm{a}, \mathrm{c}}$
}

Objective: The study objective was to evaluate the roles of mitochondrial DNA alterations in esophageal squamous cell carcinoma, with emphasis on the changes in the copy number and D310 variants of mitochondrial DNA.

Methods: Paired samples microdissected from esophageal muscles, noncancerous esophageal mucosa, cancerous esophageal squamous cell carcinoma nests, and metastatic lymph nodes of 72 patients with esophageal squamous cell carcinoma were subjected to DNA extraction. The copy number and D310 variants of mitochondrial DNA were determined by quantitative real-time polymerase chain reaction and direct sequencing, respectively.

Results: Fifty-six patients $(77.8 \%)$ with somatic D310 mutations had lower survival probability $(P=.027)$. From noncancerous esophageal mucosa to cancerous esophageal squamous cell carcinoma nests and metastatic lymph nodes, the D310 variants were decreased from 2.2 to 1.7 and 1.5 , respectively, with a trend to homoplasmy $(P=.0009)$. Concurrently, the mitochondrial DNA copy number was increased from 0.159 to 0.192 and 0.206 , respectively, $(P=$ $.024)$, especially in cigarette smokers $(P=.014)$ and heavy wine drinkers $(P=.005)$. Notably, a decrease in D310 variants $(1.5, P<.001)$ and an increase in the incidence of the homoplasmic $\mathrm{D} 310$ pattern $(P=.005)$ were observed in the matched esophageal muscle tissues. Among the 56 esophageal squamous cell carcinoma cancer nests with somatic D310 mutations, 51 (91.1\%) had D310 variants in association with their corresponding noncancerous esophageal mucosa, including $36(64.3 \%)$ fully related and $15(26.8 \%)$ partially related pairs.

Conclusion: We demonstrated that somatic D310 mutations and increase in the copy number of mitochondrial DNA are of clinical importance in esophageal squamous cell carcinoma. We also propose a model of DNA instability and clonal expansion during the carcinogenesis and progression of esophageal squamous cell carcinoma from the viewpoint of mitochondrial DNA transmission. (J Thorac Cardiovasc Surg 2010;139:189-97)

Supplemental material is available online.

Esophageal squamous cell carcinoma (ESCC) is an aggressive malignant neoplasm in patients in Asian countries. Despite advances in therapeutic modalities during the past

From the Institute of Clinical Medicine, National Yang-Ming University, ${ }^{\text {a }}$ Taipei 112, Taiwan; Institute of Emergency and Critical Care Medicine, National Yang-Ming University, ${ }^{\text {b }}$ Taipei 112, Taiwan; Department of Biochemistry and Molecular Biology, National Yang-Ming University, ${ }^{\mathrm{c}}$ Taipei 112, Taiwan; Division of Thoracic Surgery, Department of Surgery, Keelung Hospital, Department of Health, Executive Yuan, ${ }^{\mathrm{d}}$ Keelung 201, Taiwan; Division of Thoracic Surgery, Department of Surgery, Taipei Veterans General Hospital, ${ }^{\mathrm{e}}$ Taipei 112, Taiwan; Department of Chest, Taipei Veterans General Hospital, ${ }^{\mathrm{f}}$ Taipei 112, Taiwan; Division of Surgical Pathology, Department of Pathology and Laboratory Medicine, Taipei Veterans General Hospital, ${ }^{\mathrm{g}}$ Taipei 112, Taiwan; and Division of Thoracic Surgery, Department of Surgery, En Chu Kong Hospital, ${ }^{\text {h }}$ Taipei 237, Taiwan.

This work was supported by grants from the Department of Health (No. 97-04) and the National Science Council of Taiwan (NSC96-2320-B-010-006), and partially by a grant from Keelung Hospital (97-08) of the Department of Health, Executive Yuan, Taiwan.

Received for publication Sept 8, 2008; revisions received March 26, 2009; accepted for publication April 12, 2009; available ahead of print June 15, 2009.

Address for reprints: Yau-Huei Wei, PhD, Department of Biochemistry and Molecular

Biology, School of Life Sciences, National Yang-Ming University, Taipei 112,

Taiwan (E-mail: joeman@ym.edu.tw).

$0022-5223 / \$ 36.00$

Copyright (c) 2010 by The American Association for Thoracic Surgery

doi:10.1016/j.jtcvs.2009.04.007 decades in Taiwan, the survival outcome remains dismal. ${ }^{1-3}$ Several clinical and molecular prognostic factors have been investigated in patients with ESCC. ${ }^{1-3}$ However, most studies are concerned with the roles of nuclear DNA (nDNA) mutations, and less attention has been paid to mitochondrial DNA (mtDNA) alterations. Thus, appraisal of the role of mtDNA alterations in the pathophysiology of ESCC is of great clinical importance.

Each human cell contains several hundred to 1000 mitochondria, and each mitochondrion has 2 to 10 copies of mtDNA. In contrast with the heterozygotic characteristics of nDNA inherited from parents, mtDNA is transmitted through the maternal lineage. In addition, the majority of mtDNA copies in the cells of post-mitotic tissues of an individual are identical at birth with a pattern termed "homoplasmy." 4,5 Human mtDNA accumulates damages and mutations at a rate approximately 17 times greater than does the nDNA. ${ }^{5,6}$ When the mutated mtDNA molecules coexist with the wild-type mtDNA, the homoplasmy is disrupted and shifted to the so-called heteroplasmy. ${ }^{4}$

Human mtDNA is a 16,569 base-pair, double-stranded, closed-circular DNA molecule that encodes 13 polypeptides, 2 rRNAs, and a set of 22 tRNAs required for protein synthesis in mitochondria. The displacement loop located at nucleotide position (np) $16024-576$ with $1.1 \mathrm{~kb}$ in size is a noncoding 


$$
\begin{aligned}
& \text { Abbreviations and Acronyms } \\
& \text { ANOVA }=\text { analysis of variance } \\
& \text { ESCC }=\text { esophageal squamous cell carcinoma } \\
& \text { mtDNA }=\text { mitochondrial DNA } \\
& \text { nDNA }=\text { nuclear DNA } \\
& \mathrm{np} \quad=\text { nucleotide position } \\
& \mathrm{PCR} \quad=\text { polymerase chain reaction }
\end{aligned}
$$

region essential for the replication and transcription of mtDNA. ${ }^{7}$ The displacement loop has been discovered as a hot spot for mutation in several human cancers, especially in the D310 region. ${ }^{8}$

There is a polycytidine tract consisting of repeated monocytidine between np 303 and np 316 with a thymidine interposed at np 310 (ie, $-\mathrm{C}_{303} \mathrm{CCCCCC}-\mathrm{T}_{310^{-}} \mathrm{CCCCCC}_{316^{-}}$). Generally, the cytidine number before thymidine is 7 (C-7, wild type), but $6,8,9,10$, and 11 (C-6, C-8, C-9, C10, C11 variants) have also been reported in different individuals (http://www.mitomap.org). ${ }^{9}$ Such variations among human populations are referred to as D310 polymorphisms or D310 variants. Somatic D310 mutation (ie, altered D310 variants between matched cancerous and noncancerous counterparts) was recently found in several human cancers, including head and neck, lung, gastric, breast, and prostate cancers. ${ }^{10,11}$ However, little is known about such mutations in ESCC. ${ }^{12,13}$ Because of the regulatory role of the displacement loop in mtDNA replication, it is important to determine whether such D310 mutations are associated with quantitative changes in mtDNA copy number. Although changes in mtDNA copy number have been reported in several human cancers, as an increase in head and neck cancers ${ }^{14}$ or a decrease in advanced gastric cancer, breast cancer, and hepatocellular carcinomas, ${ }^{11,15-17}$ their clinical significance remains unclear.

In this study, we investigated the mtDNA alterations, mainly focused on D310 mutations and change in mtDNA copy number, and their association with the clinical outcomes of ESCC. Possible factors, including demographic data, history of cigarette smoking or alcohol drinking, and tumor characteristics, which might be related to mtDNA alterations, were also evaluated. Finally, we propose a model to explain the role of mtDNA alterations in the pathophysiology of ESCC.

\section{MATERIALS AND METHODS \\ Patient Selection}

Patients with resectable ESCC and without obvious distant organ metastasis on preoperative assessments who received complete surgical resection (including transthoracic subtotal esophagectomy, gastric tube reconstruction with esophagogastric anastomosis in the neck, and radical lymph node dissection) as their primary treatment modality at Taipei Veterans General Hospital were enrolled between 2000 and 2003. None of the patients received preoperative neoadjuvant chemotherapy or radiotherapy. The patients' pathologic data (TNM status according to the American Joint
Committee on Cancer $^{18}$ ) and clinical data (eg, smoking status, alcohol consumption, and overall survival period) were recorded in detail for systemic analysis. All patients were followed up until December 2006, and the preliminary results have been reported. ${ }^{3}$ The patients' clinical data and pathologic slides were subject to review, and a total of 72 ESCC cases were recruited for analysis in this study. Institutional review board approval from Taipei Veterans General Hospital was obtained to conduct this retrospective study (VGHIRB No: 95-11-15A).

\section{Tissue Collection and DNA Extraction}

With the assistance of an experienced pathologist, representative tumor foci without necrosis and lymphocyte infiltration on pathologic slides were located, and thin slices approximately $5 \mu \mathrm{m}$ in thickness from corresponding paraffinembedded tissue blocks were prepared for laser microdissection. Under the guidance of the hematoxylin-eosin Y stain, paired pathologically normal noncancerous esophageal mucosa and underlying esophageal muscle tissues and the cancerous ESCC nests from each patient were microdissected using a laser beam under a light microscope (Figure E1). Among the 72 patients with ESCC, 44 had lymph node metastasis, and pathologic blocks containing the metastatic lymph nodes of 37 patients were retrieved adequately for laser microdissection. The tissue samples were stored in $0.5 \mathrm{~mL}$ Eppendorf vials and mixed with $60 \mu \mathrm{L}$ QuickExtract DNA extraction solution (Epicenter, Madison, Wis) to extract total cellular DNA at $65^{\circ} \mathrm{C}$ for 3 hours. ${ }^{19}$ The quality of the extracted DNA was verified by the ratio between the absorbance at 260 and $280 \mathrm{~nm}$, and the existence of a DNA band polymerase chain reaction (PCR) amplified from 18S rRNA gene after electrophoresis and ethidium bromide staining. The DNA sample was kept at $-20^{\circ} \mathrm{C}$ until use.

\section{Sequencing of the D310 Region}

The D310 region was PCR amplified from the extracted DNA and then subjected to direct sequencing. Each $50-\mu \mathrm{L}$ PCR reaction contained $25 \mu \mathrm{L}$ of AmpliTaq Gold PCR Master Mix (Applied Biosystems, Foster City, Calif), $22 \mu \mathrm{L}$ of PCR-grade $\mathrm{H}_{2} \mathrm{O}, 1 \mu \mathrm{L}$ of each primer (H76-1: $5^{\prime}$-CACGC GATAGCATTGCGA- $3^{\prime}$ and L335: 5' -TAAGTGCTGTGGCCAGAAGC $-3^{\prime}$ ), and $1 \mu \mathrm{L}$ of sample DNA. ${ }^{20}$ The PCR conditions were set at $95^{\circ} \mathrm{C}$ for $5 \mathrm{~min}$ utes followed by 40 cycles of amplification at $95^{\circ} \mathrm{C}$ for 15 seconds, $58^{\circ} \mathrm{C}$ for 15 seconds, and $72^{\circ} \mathrm{C}$ for 30 seconds, and the final extension at $72^{\circ} \mathrm{C}$ for 7 minutes. PCR products were subject to electrophoresis on a $3 \%$ agarose gel to separate the DNA bands and visualized by ultraviolet light illumination after ethidium bromide staining. The DNA band of interest was then cut out of the gel and subject to direct sequencing. The results were compared in pairs with reference to the human mitochondrial genome database (http:// www.mitomap.org). ${ }^{9}$

\section{Determination of Mitochondrial DNA Copy Number}

The mtDNA copy number was determined as mtDNA/nDNA ratio by quantitative real-time PCR. For each $10-\mu \mathrm{L}$ reaction, $1 \mu \mathrm{L}$ of unknown DNA was amplified in a capillary containing $0.25 \mu \mathrm{L}$ of each primer $(20 \mu \mathrm{M}), 1.2 \mu \mathrm{L} 3 \mathrm{mmol} / \mathrm{L} \mathrm{MgCl}_{2}, 1 \mu \mathrm{L}$ LightCycler SYBR Green mixed reagent (Roche Applied Science, Mannheim, Germany), and 6.3 $\mu \mathrm{L} \mathrm{PCR-}$ grade $\mathrm{H}_{2} \mathrm{O}$. Also amplified were DNA samples from 143B cells $(1.25 \mathrm{ng} /$ $\mu \mathrm{L}$ ) and PCR-grade $\mathrm{H}_{2} \mathrm{O}$ as the positive and negative controls, respectively. The PCR was performed with hot start at $95^{\circ} \mathrm{C}$ for 10 minutes followed by 40 cycles of $95^{\circ} \mathrm{C}$ for 20 seconds, $62^{\circ} \mathrm{C}$ for 20 seconds, and $72^{\circ} \mathrm{C}$ for $20 \mathrm{sec}-$ onds. The sequences of primers used to amplify mtDNA (ND1 region) were mtF3212, 5'-CACCCAAGAA CAGGGTTTGT-3' and mtR3319, 5'TGGCCATGGGATTGTTGTTAA- ${ }^{\prime}$. The sequences of primers used to amplify nDNA (18S rRNA gene) were 18S1546F 5'-TAGAGG GA CAAGTGGCGTTC- ${ }^{\prime}$ and 18S1650R $5^{\prime}$-CGCTGAGCCAGTCAGTGT$3^{\prime} .{ }^{21}$ Standard curves representing the quantities of both mtDNA and nDNA related to replication threshold cycles were established by using DNA from 143B osteosarcoma cells $\left(R^{2}=0.9973\right.$ for mtDNA and $R^{2}=$ .9973 for nDNA) as previously reported. ${ }^{21}$ The mtDNA copy number of 
the 143B cell was used as the internal standard and defined as 1 . The relative mtDNA copy numbers of clinical samples were then determined accordingly. Each analysis was done in duplicate, and the value of the mean was used for data presentation.

\section{Statistics}

All statistical analyses in this study were performed using the Statistical Package for the Social Sciences, 12.0 (SPSS Inc, Chicago, Ill) and Statistics Analysis System 9.1 (SAS Institute Inc, Cary, NC). The continuous variables between groups were compared using the Student $t$ test/Mann-Whitney test, analysis of variance (ANOVA)/Kruskal-Wallis test, or paired $t$ test when appropriate. Categoric variables between groups were compared using the chi-square test, Fisher's exact test, or Cochrane-Armitage test for trend when appropriate. Survival probability was calculated and presented by the Kaplan-Meier plot. The log-rank test was used to compare different survival probabilities among different levels within each categoric variable. Possible prognostic factors associated with survival probability at a significance level of .20 or less were considered in a multivariable Cox's proportional hazard regression analysis.

\section{RESULTS}

\section{Clinical Data}

Between January 2000 and December 2003, 72 patients with ESCC (62 men, 86.1\%) with a mean age of 60.1 years were eligible for analysis. The demographic data are summarized in Table 1. Fifty-six patients $(77.8 \%)$ smoked cigarettes with a mean smoking index (packages smoked per day times years of smoking; pack-year) of $35.8 \pm 22.2$, and 57 patients $(79.2 \%)$ drank alcohol with a mean alcohol consumption index (bottles consumed per day times years of drinking; bottle-year) of $23.6 \pm 18.5$. On the basis of the American Joint Committee on Cancer staging system, 6 patients $(8.3 \%)$ were in stage I, 21 patients $(29.2 \%)$ were in stage II, 18 patients $(25.0 \%)$ were in stage III, and 27 -patients $(37.5 \%)$ were in stage IV of nonregional lymph node metastasis. The overall mean and median survival periods were 30.7 months $(95 \%$ confidence interval, 25.0-36.3) and 24.2 months (95\% confidence interval, 16.8-31.6), respectively. Eleven patients $(15.3 \%)$ underwent incomplete R1 resection because of the presence of microscopically atypical cells (3 dysplasia, 4 carcinoma in situ, 4 invasive carcinoma) in the proximal resection margin of the cervical esophagus. Although all the distal resection margins over the gastric cardia were free of carcinoma invasion, 9 patients $(12.5 \%)$ were found to have ESCC cancer nests in the gastric cardia.

\section{Distribution of Major D310 Variants in Examined Tissues of Patients With Esophageal Squamous Cell Carcinoma}

Distributions of the major D310 variants of the examined tissues are summarized in Table 2. By taking the noncancerous esophageal mucosa of patient A01 as an example, 3 kinds of D310 variants were found (C-8, C-9, and C-10; heteroplasmic), and $\mathrm{C}-8$ was the major variant (Table E1). Among the major D310 variants in the examined tissues, C-8 was the most common followed by C-7. C-8 as the major variant was noted in
$56.9 \%(n=41)$ of 72 muscle tissues, $38.9 \%(n=28)$ of 72 noncancerous mucosa, $45.8 \%(\mathrm{n}=33)$ of 72 ESCC nests, and $48.6 \%(n=18)$ of 37 metastatic lymph nodes.

\section{D310 Sequence Variations in Noncancerous Esophageal Mucosa and Paired Cancerous Esophageal Squamous Cell Carcinoma Nests}

Changes in D310 variants between the noncancerous esophageal mucosa and the paired cancerous ESCC nests in each patient were compared, and 5 types of alterations were classified, including 16 patients $(22.2 \%)$ with type I (homoplasmic to the same homoplasmic variant), 8 patients (11.1\%) with type II (homoplasmic to heteroplasmic), 23 patients $(31.9 \%)$ with type III (heteroplasmic to heteroplasmic), 23 patients $(31.9 \%)$ with type IV (heteroplasmic to homoplasmic), and 2 patients $(1.5 \%)$ with type $\mathrm{V}$ (one homoplasmic variant to another homoplasmic variant) alterations (Tables 3 and E1; Figure E2). We defined type II, III, IV, and V alterations as D310 mutations $(\mathrm{n}=56$, $77.8 \%$ ) resulting from any shift in the proportions of D310 variants between noncancerous esophageal mucosa and paired cancerous ESCC nests, and type I alteration $(\mathrm{n}=16,22.2 \%)$ was regarded as no mutation. By using patient A01 as an example (Table E1), C-8 (major), C-9, and $\mathrm{C}-10$ variants coexisting in the noncancerous esophageal mucosa were changed to C-9 (major), C-8, and C-10 variants coexisting in the paired cancerous ESCC nest. We thus defined this patient as having type III D310 alteration with D310 mutation.

\section{Relationship Between D310 Variants in Cancerous Esophageal Squamous Cell Carcinoma Nests and Matched Noncancerous Esophageal Mucosa}

The relationship between D310 variants in the cancerous ESCC nests and the corresponding noncancerous esophageal mucosa of each patient was analyzed and grouped as follows: (1) fully related $(n=52,72.2 \%)$ : All the D310 variants of the cancerous ESCC nests already existed in the paired noncancerous esophageal mucosa (eg, patient A01), including 16 $(22.2 \%)$ without D310 mutations and $36(50 \%)$ with D310 mutations; (2) partially related $(\mathrm{n}=15,20.8 \%)$ : Some but not all of the D310 variants of the cancerous ESCC nests existed in the paired noncancerous esophageal mucosa (eg, patient B08), and all of them harbored D310 mutations; (3) not related $(n=5,6.9 \%)$ : None of the D310 variants of the cancerous ESCC nests existed in the paired noncancerous esophageal mucosa (eg, patient E12), and all of them harbored D310 mutations (Tables 3 and E1).

\section{Prognostic Roles of Somatic D310 Mutation and Other Factors}

There were 56 patients $(77.8 \%)$ with ESCC harboring D310 mutations with poorer prognosis $(P=.027, \log$-rank test) (Figure 1, $A$; Table 1). Other clinical factors, including 
TABLE 1. Demographic data and possible prognostic factors affecting survival probability in patients with esophageal squamous cell carcinoma

\begin{tabular}{|c|c|c|c|c|c|c|}
\hline \multirow{2}{*}{$\begin{array}{c}\text { Demographic } \\
\text { data/prognostic factors }(\%)\end{array}$} & \multirow{2}{*}{$\begin{array}{c}\text { Overall survival } \\
\text { Mean }(95 \% \text { CI) }(\mathbf{m o})\end{array}$} & \multirow{2}{*}{$\begin{array}{r}\text { Univariable } \\
P \text { (log-rank) }\end{array}$} & & \multicolumn{2}{|c|}{ Multivariable } & \multirow[b]{2}{*}{$P($ Cox regression $)$} \\
\hline & & & & Hazard ratio & $95 \% \mathrm{CI}$ & \\
\hline D310 mutation & & .027 & & & & .002 \\
\hline Yes $(\mathrm{n}=56)(77.8)$ & $26.9(20.7-33.0)$ & & & 1.000 & & \\
\hline No $(\mathrm{n}=16)(22.2)$ & $40.9(30.3-51.5)$ & & & 0.258 & $0.109-0.614$ & \\
\hline Gender & & .615 & & & & \\
\hline Male $(\mathrm{n}=62)(86.1)$ & $30.0(23.8-36.3)$ & & & & & \\
\hline Female $(\mathrm{n}=10)(13.9)$ & $34.9(23.0-46.8)$ & & & & & \\
\hline \multicolumn{7}{|l|}{ Presenting symptoms } \\
\hline Difficulty in swallowing & & .017 & & & & .329 \\
\hline Yes $(\mathrm{n}=58)(80.6)$ & $25.9(20.5-31.3)$ & & & & & \\
\hline No $(n=14)(19.4)$ & $46.4(33.4-59.5)$ & & & & & \\
\hline Body weight loss & & .829 & & & & \\
\hline Yes $(n=20)(27.8)$ & $29.4(19.3-39.4)$ & & & & & \\
\hline No $(\mathrm{n}=52)(72.2)$ & $30.3(23.8-36.7)$ & & & & & \\
\hline \multicolumn{7}{|l|}{ Special habit } \\
\hline Cigarette smoking & & .258 & & & & \\
\hline Yes $(\mathrm{n}=56)(77.8)$ & $28.7(22.4-35.0)$ & & & & & \\
\hline No $(\mathrm{n}=16)(22.2)$ & $36.0(24.8-47.1)$ & & & & & \\
\hline Alcohol drinking & & .5773 & & & & \\
\hline Yes $(\mathrm{n}=57)(79.2)$ & $29.7(23.4-36.1)$ & & & & & \\
\hline No $(n=15)(20.8)$ & $31.4(21.4-41.5)$ & & & & & \\
\hline \multicolumn{7}{|l|}{ Pathologic findings } \\
\hline Esophageal resection margin invasion* & & .073 & & & & .081 \\
\hline Yes $(n=11)(15.3)$ & $18.7(9.67-27.7)$ & & & & & \\
\hline No $(n=61)(84.7)$ & $32.5(26.3-38.7)$ & & & & & \\
\hline Gastric cardia invasion & & .001 & & & & .383 \\
\hline Yes $(n=9)(12.5)$ & $10.1(3.5-16.7)$ & & & & & \\
\hline No $(n=63)(87.5)$ & $33.2(27.3-39.2)$ & & & & & \\
\hline T-status (depth of tumor invasion) & & .005 & & & & .004 \\
\hline $\mathrm{T} 1(\mathrm{n}=7)(9.7)$ & $45.0(26.9-63.1)$ & & T1 vs T4 & 0.232 & $0.060-0.896$ & .034 \\
\hline $\mathrm{T} 2(\mathrm{n}=13)(18.1)$ & $38.4(27.4-49.4)$ & & $\mathrm{T} 2$ vs $\mathrm{T} 4$ & 0.235 & $0.092-0.599$ & .002 \\
\hline $\mathrm{T} 3(\mathrm{n}=29)(40.3)$ & $30.7(23.4-38.0)$ & & $\mathrm{T} 3$ vs $\mathrm{T} 4$ & 0.314 & $0.149-0.658$ & .002 \\
\hline $\mathrm{T} 4(\mathrm{n}=23)(31.9)$ & $14.5(9.3-19.6)$ & & T4 vs T4 & 1.000 & & \\
\hline N-status & & $<.001$ & & & & .007 \\
\hline $\mathrm{N}(-)(\mathrm{n}=28)(38.9)$ & $44.0(35.2-52.7)$ & & & 0.410 & $0.197-0.855$ & \\
\hline$N(+)(n=44)(61.1)$ & $21.5(15.9-27.2)$ & & & 1.000 & & \\
\hline M-status & & .117 & & & & .689 \\
\hline $\mathrm{M} 0(\mathrm{n}=45)(62.5)$ & $35.2(28.0-42.5)$ & & & & & \\
\hline M1a $(\mathrm{n}=12)(16.7)$ & $22.4(12.5-32.3)$ & & & & & \\
\hline M1b $(\mathrm{n}=15)(20.8)$ & $22.9(11.8-34.0)$ & & & & & \\
\hline Cancer stage (AJCC) & & .043 & & & & .363 \\
\hline $\mathrm{I}(\mathrm{n}=6)(8.3)$ & $48.6(28.4-68.9)$ & & & & & \\
\hline II $(\mathrm{n}=21)(29.2)$ & $38.0(28.8-47.2)$ & & & & & \\
\hline $\mathrm{III}(\mathrm{n}=18)(25.0)$ & $22.2(14.1-30.3)$ & & & & & \\
\hline IV $(\mathrm{n}=27)(37.5)$ & $22.4(14.9-29.8)$ & & & & & \\
\hline \multicolumn{7}{|l|}{ Postoperative adjuvant therapy } \\
\hline Radiotherapy & & 9395 & & & & \\
\hline Yes $(n=22)(30.6)$ & $29.4(20.5-38.2)$ & & & & & \\
\hline No $(n=50)(69.4)$ & $30.5(23.6-37.3)$ & & & & & \\
\hline Chemotherapy & & .2378 & & & & \\
\hline Yes $(n=26)(36.1)$ & $25.3(18.5-32.1)$ & & & & & \\
\hline No $(n=46)(63.9)$ & $33.3(25.6-40.9)$ & & & & & \\
\hline
\end{tabular}

$\overline{A J C C}$, American Joint Committee on Cancer; $C I$, confidence interval. *Cervical esophageal resection margins invasion indicates R1 resection, that is, atypical cells (3 dysplasia, 4 carcinoma in situ, 4 invasive carcinoma) were found in the resection margin during microscopic examination. 
TABLE 2. Distribution of D310 patterns and mtDNA copy numbers among the esophageal muscular tissues, noncancerous esophageal mucosa, cancerous esophageal squamous cell carcinoma nests, and metastatic lymph nodes in 72 patients with esophageal squamous cell carcinoma

\begin{tabular}{|c|c|c|c|c|c|c|c|}
\hline & $\underline{\text { Reference tissues }}$ & Target tissues & & & & & \\
\hline & $\begin{array}{c}\text { Esophageal } \\
\text { muscular tissues }\end{array}$ & $\begin{array}{c}\text { Noncancerous } \\
\text { esophageal mucosa }\end{array}$ & $\begin{array}{l}\text { Cancerous } \\
\text { ESCC nests }\end{array}$ & $\begin{array}{c}\text { Metastatic } \\
\text { lymph nodes }\end{array}$ & & & \\
\hline & $\mathrm{n}=72(100)$ & $\mathrm{n}=72(100)$ & $n=72(100)$ & $\mathbf{n}=37(100)$ & $P$ value $\|$ & $P$ value & $P$ value\# \\
\hline \multicolumn{8}{|l|}{ D310 parameters } \\
\hline \multicolumn{8}{|c|}{ Pattern of D310 distribution } \\
\hline Homoplasmic $(\%)$ & $43(59.7)$ & $26(36.1)$ & $41(56.9)$ & $25(67.6)$ & $.005^{*}$ & $.012 *$ & $<.001 \ddagger$ \\
\hline Heteroplasmic $(\%)$ & $29(40.3)$ & $46(63.9)$ & $31(43.1)$ & $12(32.4)$ & & & \\
\hline \multicolumn{8}{|l|}{ No. of D310 variants } \\
\hline Mean \pm SD & $1.5 \pm 0.8$ & $2.2 \pm 1.0$ & $1.7 \pm 1.0$ & $1.5 \pm 0.8$ & $<.001 \dagger$ & $.002 \dagger$ & $.001 \S$ \\
\hline Median & 1.0 & 2.0 & 1.0 & 1.0 & & & \\
\hline \multicolumn{8}{|l|}{ Major D310 variant } \\
\hline C-7 (\%) & $25(34.7)$ & $29(40.3)$ & $27(37.5)$ & $13(35.1)$ & $.491 *$ & $.732 *$ & $.589 \ddagger$ \\
\hline Non C-7 (\%) & $47(65.3)$ & $43(59.7)$ & $45(62.5)$ & $24(64.9)$ & & & \\
\hline C-8 $(\%)$ & $41(56.9)$ & $28(38.9)$ & $33(45.8)$ & $18(48.6)$ & & & \\
\hline C-9 (\%) & $6(8.3)$ & $11(15.3)$ & $9(12.5)$ & $5(13.5)$ & & & \\
\hline Others $(\%)$ & $0(0)$ & $4(5.6)$ & $3(4.2)$ & $1(2.7)$ & & & \\
\hline \multicolumn{8}{|l|}{ mtDNA copy no. } \\
\hline Mean \pm SD & ND & $0.159 \pm 0.056$ & $0.192 \pm 0.111$ & $0.206 \pm 0.113$ & ND & $.004 \dagger$ & $.024 \S$ \\
\hline
\end{tabular}

advanced T status $(P=.005)$, positive lymph node metastasis $(P<.001)$, late cancer stage $(P=.043)$, gastric cardia invasion $(P=.001)$, invasion of the cervical esophageal resection margins $(P=.073)$, and symptoms of swallowing difficulty $(P=.017)$, were associated with shorter survival. After conducting a Cox's regression with stepwise analysis, we found that D310 mutation $(P=.002)$, advanced T status $(P=.004)$, and positive lymph node metastasis $(P=.007)$ were independent risk factors related to worse outcomes (Table 1). We found that patients with a higher degree of D310 heteroplasmy (ie, >2 D310 variants) in the noncancerous mucosa had a lower survival probability than did patients with a lower degree of D310 heteroplasmy (ie, $\leq 2$ D310 variants $)(P=.005$; Figure $1, B)$.

\section{Alterations of the D310 Patterns and Mitochondrial DNA Copy Numbers in Tissues of Patients With Esophageal Squamous Cell Carcinoma}

On average, each noncancerous esophageal mucosa harbored 2.2 kinds of D310 variants, each cancerous ESCC nest harbored 1.7 kind of D310 variants, and each metastatic lymph node harbored 1.5 kinds of D310 variants. There was a stepwise decrease of D310 variants when ESCC progressed $(P=.001$, ANOVA) and an increase in the incidence of homoplasmic D310 pattern from noncancerous esophageal mucosa $(26 / 72,36.1 \%)$ to cancerous ESCC nests $(41 / 72,56.9 \%)$ and to metastatic lymph nodes $(25 /$ $37,67.6 \%)(P=.0009$, Cochrane-Armitage test for trend) (Table 2). The mean mtDNA copy number showed a stepwise increase from the noncancerous esophageal mucosa
$(0.159, \mathrm{n}=72)$ to the cancerous ESCC nests $(0.192, \mathrm{n}=$ 72) $(P=.004$, paired $t$ test $)$ and then to the metastatic lymph nodes $(0.206, \mathrm{n}=37)(P=.024$, ANOVA) (Table 2$)$ during ESCC progression. In the pathologically normal tissues, the kinds of D310 variants in the esophageal muscle (1.5) were significantly less than those in paired noncancerous esophageal mucosa (2.2) $(P<.001$, paired $t$ test), with a higher incidence of heteroplasmic pattern in the noncancerous esophageal mucosa $\left(P=.005, \chi^{2}\right.$ test $)$ (Table 2$)$.

\section{Factors Related to Somatic D310 Mutation and Mitochondrial DNA Copy Number Alteration}

The possible contributory factors for somatic D310 mutations are old age $(P=.015)$, heteroplasmy with multiple D310 variants $(P<.001)$, and major D310 variants other than $\mathrm{C}-7$ in noncancerous esophageal mucosa $(P<.001)$ (Table 4). To compare the changes of mtDNA copy number, we defined the mtDNA copy ratio as the mtDNA copy number of the cancerous ESCC nest over the paired noncancerous esophageal mucosa in each patient. Male patients $(P=.012)$, cigarette smokers $(P=.014)$, alcohol drinkers $(P=.005)$, and presence of the heteroplasmic D310 pattern $(P=.015)$ and major variants other than $\mathrm{C}-7(P=.014)$ in the noncancerous esophageal mucosa are associated with an elevated mtDNA copy ratio (Table 4).

\section{Quantitative Changes of Mitochondrial DNA Copy Number When Harboring D310 Mutation}

Among the 56 patients with somatic D310 mutations, 23 $(41.1 \%)$ had type IV alteration (heteroplasmic to 
TABLE 3. Differences of mtDNA copy ratios according to types of D310 alteration and D310 clonal relationships

\begin{tabular}{|c|c|c|c|}
\hline Classification & Case No. $(\%) \ddagger$ & $\begin{array}{c}\text { mtDNA } \\
\text { copy ratio }\end{array}$ & $P$ value \\
\hline $\begin{array}{l}\text { Without somatic D310 } \\
\text { mutation }(\mathrm{n}=16)\end{array}$ & $16(22.2)$ & $1.09 \pm 0.41$ & $.319 \dagger$ \\
\hline \multicolumn{4}{|l|}{ Type of D310 alteration } \\
\hline $\begin{array}{l}\text { I (homoplasmic to } \\
\text { homoplasmic) }\end{array}$ & $16(22.2)$ & $1.09 \pm 0.41$ & \\
\hline \multicolumn{4}{|l|}{ Clonal relationship } \\
\hline Fully related & $16(22.2)$ & $1.09 \pm 0.41$ & \\
\hline Partially related & ND & ND & \\
\hline Not related & ND & ND & \\
\hline $\begin{array}{l}\text { With somatic D310 } \\
\text { mutation }(\mathrm{n}=56)\end{array}$ & $56(77.8)$ & $1.28 \pm 0.72$ & $.008 \dagger$ \\
\hline \multicolumn{4}{|l|}{ Type of D310 alteration } \\
\hline $\begin{array}{l}\text { II (homoplasmic to } \\
\text { heteroplasmic) }\end{array}$ & $8(11.1)$ & $0.91 \pm 0.31$ & $.048 *$ \\
\hline $\begin{array}{l}\text { III (heteroplasmic to } \\
\text { heteroplasmic) }\end{array}$ & $23(31.9)$ & $1.21 \pm 0.69$ & \\
\hline $\begin{array}{l}\text { IV (heteroplasmic to } \\
\text { homoplasmic) }\end{array}$ & $23(31.9)$ & $1.50 \pm 0.80$ & \\
\hline $\begin{array}{l}\text { V (A homoplasmic to } \\
\text { B homoplasmic) }\end{array}$ & $2(1.5)$ & $1.12 \pm 0.43$ & \\
\hline \multicolumn{4}{|l|}{ Clonal relationship } \\
\hline Fully related & $36(50)$ & $1.35 \pm 0.68$ & $.047 *$ \\
\hline Partially related & $15(20.8)$ & $1.02 \pm 0.67$ & \\
\hline Not related & $5(6.9)$ & $1.52 \pm 1.05$ & \\
\hline
\end{tabular}

$N D$, Not determined; $m t D N A$ copy ratio, mtDNA copy number of cancerous ESCC nest/paired noncancerous esophageal mucosa. *ANOVA/Kruskall-Wallis. $\dagger$ Paired $t$ test (changes of the mtDNA copy number between the cancerous ESCC nest and the paired noncancerous mucosa). $\ddagger$ Overall percentage.

homoplasmic, ie, shifted to a single D310 variant) and 36 $(69.2 \%)$ had D310 variants in the ESCC cancerous nests fully related to their noncancerous esophageal mucosa (Table 3). Those with type IV alteration had a higher mtDNA copy ratio than did those with types II, III, and V alterations $(P=.048)$. Moreover, patients with D310 variants in the cancerous ESCC nests fully related to their paired noncancerous esophageal mucosa also had a higher mtDNA copy ratio compared with those who harbored only partially related D310 variants $(P=.047)$ (Table 3).

\section{DISCUSSION}

Somatic D310 mutations and their clinical significance in human cancers have been recognized in the past decade, ${ }^{10,11,15-17}$ especially in head and neck cancers. ${ }^{22}$ In recent years, somatic D310 mutations have been detected in ESCC. ${ }^{12,13}$ We demonstrated in this study that somatic D310 mutation is an independent prognostic factor in patients with ESCC (Table 1). Heteroplasmic D310 variants and major variants other than $\mathrm{C}-7$ in the noncancerous esophageal mucosa are associated with somatic D310 mutations (Table 4). Previous studies of human lung cancers showed that somatic D310 mutations occur more frequently if the major D310 variants in matched blood lymphocytes are non-C-7 variants and heteroplasmic. ${ }^{10,23}$ Generally, the incidence of D310 mutations in cancers in the Caucasian population is approximately $20 \%$, with the highest in gastric cancer $(62.5 \%)$ and lowest in prostate and ovarian cancers. ${ }^{10}$ For patients with ESCC, the incidence of D310 mutation was approximately $30 \% .{ }^{12,13}$ However, the incidence of D310 mutation was higher $(77.8 \%$ ) in our series. D310 polymorphisms (C-7 vs non-C-7) among different populations may explain this disparity. C-7 (wild type) is the most common variant in Caucasian populations, whereas most patients with ESCC in Taiwan (43/72, 59.7\%) harbored major D310 variants other than C-7 in the noncancerous esophageal mucosa. As mentioned above, non-C-7 variants are a risk factor for somatic D310 mutation, and patients with ESCC would be prone to somatic D310 mutation when the corresponding noncancerous esophageal mucosa harbors D310 variants other than C-7, which might explain the high mutation rate in Taiwanese patients with ESCC. Another possible explanation is that the samples we studied were obtained from laser microdissection and free from contamination with different cell types, and thus of higher homogeneity. We believe that the power to differentiate D310 mutations is higher when tissues are obtained from microdissection.

It is noteworthy that a heteroplasmic to homoplasmic shift of D310 variants and an increase in mtDNA copy number were observed in the progression from noncancerous esophageal mucosa to cancerous ESCC nests and then to metastatic lymph nodes (Table 2). This can be explained by Nowell' ${ }^{24}$ hypothesis of cancer evolution, which states that most cancers arise from heterogeneous precancerous lesions (with heteroplasmic D310 pattern), in which specific clones acquire a proliferation advantage (increase of copy number), followed by subsequent expansion of these clones (with homoplasmic D310 pattern). To confirm the notion, we further evaluated the associations of D310 patterns, mtDNA copy number, and D310 clonal relationship between the noncancerous esophageal mucosa and the paired cancerous ESCC nests among 56 patients with ESCC harboring D310 mutations (Table 3). We found that 23 $(41.1 \%)$ of the 56 patients exhibited a type IV heteroplasmic to homoplasmic D310 alteration (ie, to a single clone) and had a higher mtDNA copy ratio (ie, increased clonal quantity) (Table $3, P=.048)$. Fifty-one $(91.1 \%)$ of the 56 cancerous nests had D310 clonal relationship with their noncancerous esophageal mucosa, including $36(64.3 \%)$ fully related and $15(26.8 \%)$ partially related. Moreover, $36(64.3 \%)$ of the 56 patients who had mutant D310 variants in the cancerous ESCC nests fully related to their noncancerous esophageal mucosa had a higher mtDNA copy ratio than did those patients with a partially related relationship (Table $4, P=.047$ ). On the basis of these findings, we propose a model of clonal expansion during ESCC progression from the viewpoint of mtDNA transmission 

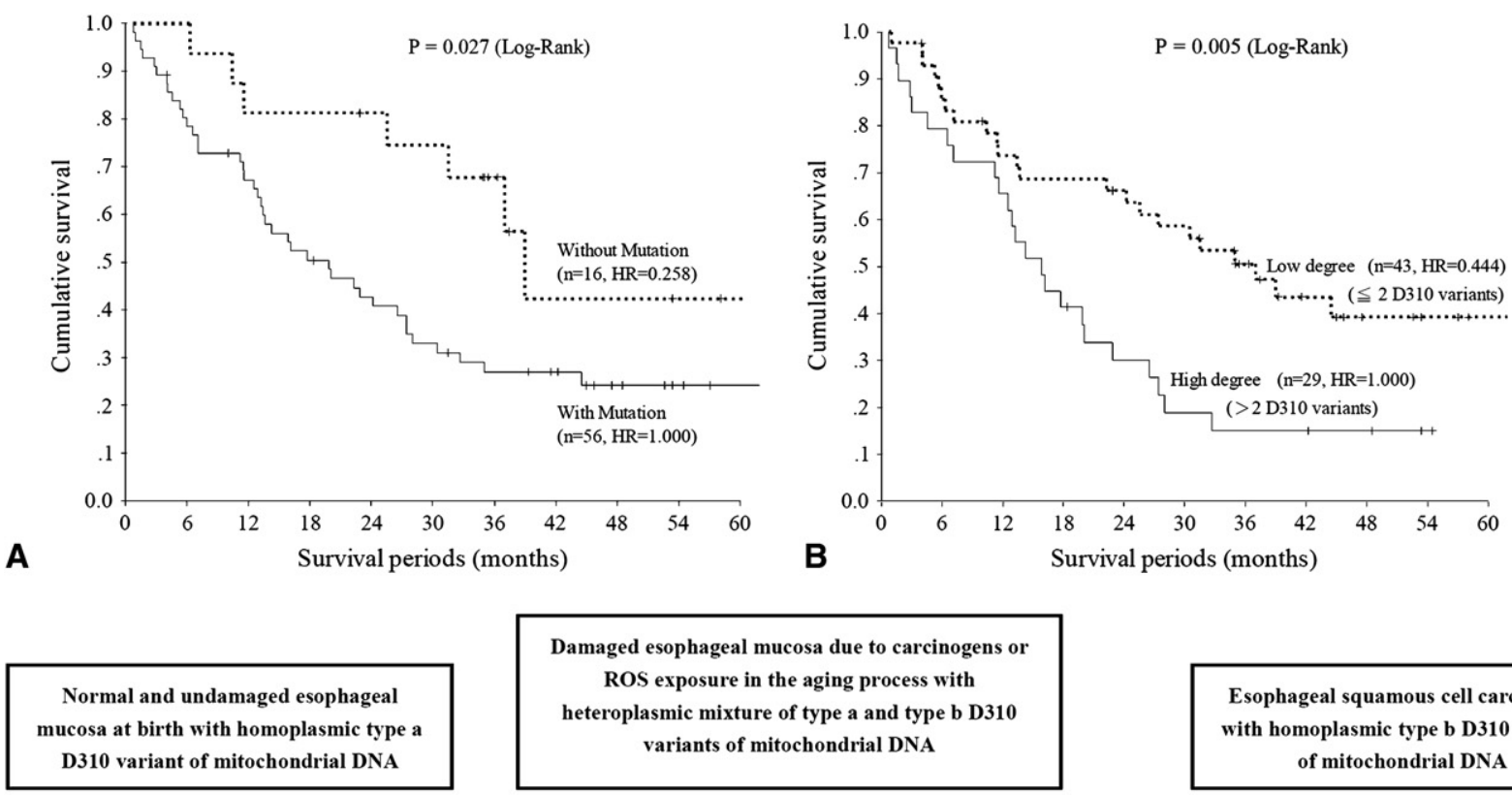

Damaged esophageal mucosa due to carcinogens or ROS exposure in the aging process with heteroplasmic mixture of type a and type b D310 variants of mitochondrial DNA

Esophageal squamous cell carcinoma with homoplasmic type b D310 variant of mitochondrial DNA
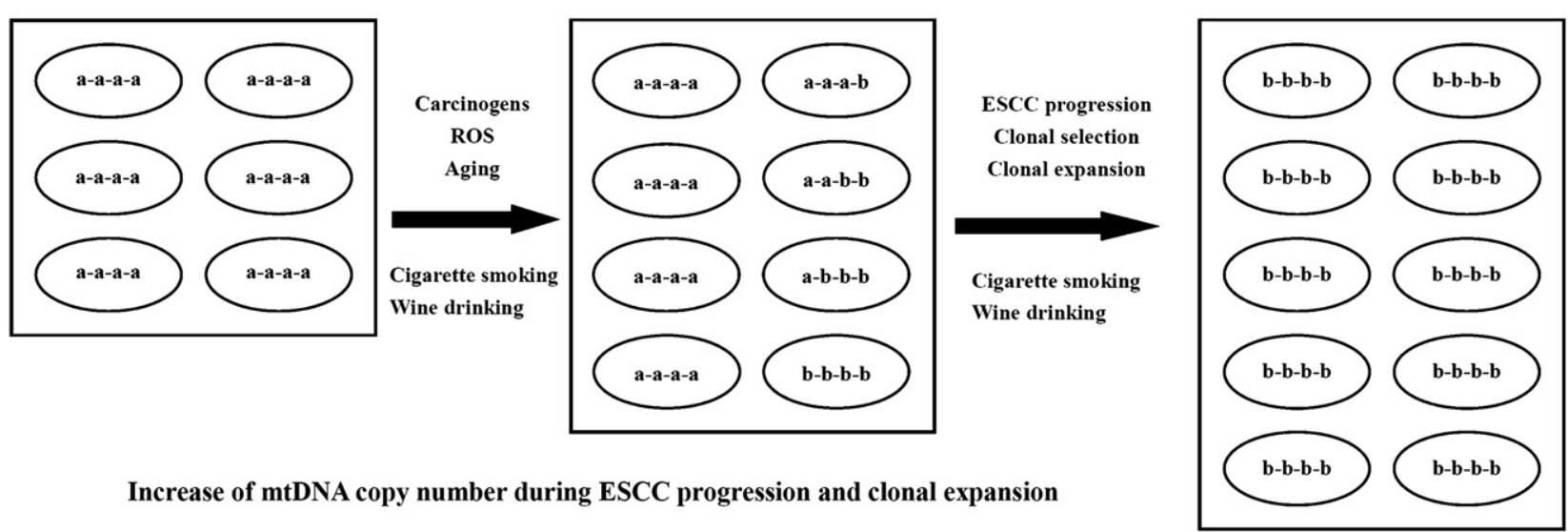

Increase of mtDNA copy number during ESCC progression and clonal expansion

Cigarette smoking Wine drinking 西

(2)

C

FIGURE 1. A, Comparison of survival between patients with ESCC with and without somatic D310 mutations of mtDNA. Patients without D310 mutations $(\mathrm{n}=16)$ had better survival probability and lower hazard ratio than those with $\mathrm{D} 310$ mutations $(\mathrm{n}=56)$. B, Comparison of the survival between patients with ESCC according to the degree of heteroplasmic D310 variation in noncancerous esophageal mucosa. Patients with lower degree heteroplasmy of mtDNA $(\mathrm{n}=$ 43) had better survival probability and lower hazard ratio than those with higher degree heteroplasmy of mtDNA $(n=29)$. C, Proposed model for the role of mtDNA alterations in ESCC is illustrated. During the aging process with accumulative damages, heteroplasmic mtDNA variants may coexist in the pathologically normal esophageal mucosa, and the quantity of total mtDNA may increase to compensate for the defects in mtDNA. When carcinogenesis is initiated or cancer is progressed, specific mtDNA variants harbored by the original malignant clone(s) are amplified during the process of clonal expansion. $H R$, Hazard ratio; ROS, reactive oxygen species; $E S C C$, esophageal squamous cell carcinoma; $m t D N A$, mitochondrial DNA.

(Figure 1, $C$, middle and right). Moreover, cigarette smoking $(P=.014)$ and alcohol consumption $(P=.005)$ were highly associated with the increase in the mtDNA copy number (Table 4).

Generally, the mtDNA molecules in an individual are assumed identical at birth, and the characteristics of D310 variants in normal esophageal muscles and paired noncancerous esophageal mucosa are supposed to be identical and concordant. ${ }^{4}$ However, the percentage of homoplasmic D310 variants in esophageal muscle tissue $(43 / 72,59.7 \%)$ was higher than that of the paired noncancerous esophageal mucosa $(26 / 72,36.1 \%)(P=.005)$, and esophageal mucosa had more D310 variants than did the corresponding esophageal muscle (2.2 vs $1.5, P=.002$, Table 2 ). This discordance may be explained by a model of accumulated damages in mtDNA during the aging process, ${ }^{4,5}$ because mucosa is the barrier of the underlying muscles (Figure 1, $C$, left). This indicates that the pathologically normal esophageal mucosa may be molecularly abnormal because of accumulated damage at the DNA level. 
TABLE 4. Factors related to the D310 mutation and mtDNA copy ratios in patients with esophageal squamous cell carcinoma

\begin{tabular}{|c|c|c|c|c|c|}
\hline \multirow[b]{2}{*}{$\begin{array}{c}\text { Clinical } \\
\text { parameters }\end{array}$} & \multicolumn{3}{|c|}{ D310 mutation } & \multicolumn{2}{|c|}{$\begin{array}{c}\text { mtDNA } \\
\text { DNA copy ratio } \ddagger \\
\end{array}$} \\
\hline & $\begin{array}{c}\text { Yes } \\
(\mathbf{n}=\mathbf{5 6})\end{array}$ & $\begin{array}{c}\text { No } \\
(n=16)\end{array}$ & $\begin{array}{c}P \\
\text { value }\end{array}$ & $\begin{array}{l}\text { Mean } \\
\pm \text { SD }\end{array}$ & $\begin{array}{c}P \\
\text { value }\end{array}$ \\
\hline Age $(y)($ mean \pm SD $)$ & $\begin{array}{r}62.1 \pm \\
12.1\end{array}$ & $\begin{array}{r}53.3 \pm \\
13.4\end{array}$ & $.015^{*}$ & ND & \\
\hline \multicolumn{6}{|l|}{ Gender } \\
\hline Male $(n=62)$ & 48 & 14 & $.855 \dagger$ & $1.28 \pm 0.70$ & $.012 *$ \\
\hline Female $(\mathrm{n}=10)$ & 8 & 2 & & $0.97 \pm 0.24$ & \\
\hline \multicolumn{6}{|l|}{ Cigarette smoking } \\
\hline Yes $(n=56)$ & 43 & 13 & $.705 \dagger$ & $1.33 \pm 0.71$ & $.014^{*}$ \\
\hline No $(n=16)$ & 13 & 3 & & $0.90 \pm 0.24$ & \\
\hline \multicolumn{6}{|l|}{ Alcohol drinking } \\
\hline Yes $(\mathrm{n}=51)$ & 42 & 15 & $.164 \dagger$ & $1.31 \pm 0.71$ & $.005^{*}$ \\
\hline No $(n=21)$ & 14 & 1 & & $0.96 \pm 0.29$ & \\
\hline \multicolumn{6}{|l|}{$\begin{array}{l}\text { D310 variants in } \\
\text { noncancerous } \\
\text { esophageal mucosa }\end{array}$} \\
\hline $\begin{array}{l}\text { No. of variants } \\
\quad(\text { mean } \pm \mathrm{SD})\end{array}$ & $2.5 \pm 1.0$ & 1.0 & $<.001 *$ & ND & \\
\hline \multicolumn{6}{|l|}{ Distribution pattern } \\
\hline $\begin{array}{l}\text { Heteroplasmy } \\
\qquad(\mathrm{n}=46)\end{array}$ & 46 & 0 & $<.001 \dagger$ & $1.35 \pm 0.76$ & $.015^{*}$ \\
\hline $\begin{array}{l}\text { Homoplasmy } \\
\qquad(\mathrm{n}=26)\end{array}$ & 10 & 16 & & $1.02 \pm 0.38$ & \\
\hline \multicolumn{6}{|l|}{ Major D310 variant } \\
\hline $\mathrm{C}-7(\mathrm{n}=29)$ & 13 & 16 & $<.001 \dagger$ & $1.03 \pm 0.39$ & $.014^{*}$ \\
\hline Non-C-7 $(n=43)$ & 43 & 0 & & $1.37 \pm 0.77$ & \\
\hline \multicolumn{6}{|l|}{ Cancer stage } \\
\hline \multicolumn{6}{|l|}{ T-status } \\
\hline $\mathrm{T} 1(\mathrm{n}=7)$ & 6 & 1 & $.388 \dagger$ & $1.37 \pm 0.93$ & $.382 \ddagger$ \\
\hline $\mathrm{T} 2(\mathrm{n}=13)$ & 10 & 3 & & $1.32 \pm 0.80$ & \\
\hline T3 $(n=29)$ & 24 & 5 & & $1.06 \pm 0.47$ & \\
\hline $\mathrm{T} 4(\mathrm{n}=23)$ & 16 & 7 & & $1.36 \pm 0.70$ & \\
\hline \multicolumn{6}{|l|}{$\mathrm{N}$-status } \\
\hline $\mathrm{N}(-)(\mathrm{n}=28)$ & 22 & 6 & $.897 \dagger$ & $1.20 \pm 0.65$ & $.745^{*}$ \\
\hline $\mathrm{N}(+)(\mathrm{n}=44)$ & 34 & 10 & & $1.25 \pm 0.68$ & \\
\hline \multicolumn{6}{|l|}{ M-status } \\
\hline M0 $(n=45)$ & 36 & 9 & $.564 \dagger$ & $1.34 \pm 0.71$ & $.158 \ddagger$ \\
\hline M1a $(\mathrm{n}=12)$ & 9 & 3 & & $1.18 \pm 0.71$ & \\
\hline M1b $(n=15)$ & 11 & 4 & & $0.97 \pm 0.32$ & \\
\hline \multicolumn{6}{|l|}{ Cancer stage (AJCC) } \\
\hline $\mathrm{I}(\mathrm{n}=6)$ & 5 & 1 & $.346 \dagger$ & $1.11 \pm 0.71$ & $.271 \ddagger$ \\
\hline $\mathrm{II}(\mathrm{n}=21)$ & 18 & 3 & & $1.34 \pm 0.73$ & \\
\hline III $(\mathrm{n}=18)$ & 13 & 5 & & $1.42 \pm 0.73$ & \\
\hline IV $(n=27)$ & 20 & 7 & & $1.06 \pm 0.53$ & \\
\hline
\end{tabular}

AJCC, American Joint Committee on Cancer; $S D$, standard deviation; $N D$, not determined. ${ }^{*} t$ test/Mann-Whitney test. $\dagger$ Chi-square test. $\ddagger$ ANOVA/Kruskall-Wallis.

The aforementioned findings led us to conclude that (1) heteroplasmic D310 variants of mtDNA in pathologically normal esophageal mucosa may be a result of accumulated damage, (2) D310 mutations of mtDNA in cancerous nests are highly associated with the prognosis of patients with ESCC, (3) the change from heteroplasmic to homoplasmic D310 variants and an increase in mtDNA copy number suggest a clonal expansion during ESCC progression, and (4) cigarette smoking and alcohol consumption are highly associated with an increase in mtDNA copy number.

Observation of multiple D310 variants in the noncancerous esophageal mucosa led us to examine whether the degree of heteroplasmy of the mtDNA in pathologically normal mucosa affected the clinical outcome of ESCC. On the basis of the mean and median number of D310 variants in the noncancerous esophageal mucosa being 2.2 and 2.0, respectively, we defined those who had less than 2 D310 variants $(n=43)$ as the low heteroplasmy group and those who had more than 2 D310 variants $(\mathrm{n}=29)$ as the high heteroplasmy group. The results showed that high heteroplasmy was associated with lower survival probability $(P=.005$; Figure $1, B)$. This suggests that unstable mtDNA with multiple variants (heteroplasmic mtDNA) in the noncancerous esophageal mucosa is a poor prognostic factor for patients with ESCC, even if the pathologic examination of their mucosa looked "normal."

The mtDNA copy number has been shown to change in many human cancers. An increase in the mtDNA copy number was reported in head and neck cancers ${ }^{14}$ and ESCC as shown in this study. A decrease in mtDNA copy number was noted in advanced hepatocellular carcinoma, gastric cancer, breast cancers, and advanced lung cancers with drug-resistance after neoadjuvant chemotherapy. ${ }^{11,15-17,21}$ On the basis of the mechanism of clonal expansion, the increase in mtDNA copy number might be a compensation for the damaged mtDNA to maintain mitochondrial function. ${ }^{14}$ When cancer progresses to advanced stages because of excess damage, decompensation may be followed with a decrease in mtDNA copy number, which results in impaired mitochondrial function and the Warburg effect. ${ }^{25}$ The roles of mtDNA copy number alterations in human cancers warrant further study.

\section{CONCLUSIONS}

We have demonstrated that mtDNA alterations are associated with the progression and prognosis of ESCC. The somatic D310 mutations, which indicate mtDNA instability, may play a role in the pathophysiology of ESCC. Whether such mtDNA alterations affect the bioenergetic function of mitochondria in affected tissues of patients with ESCC requires further investigation.

We thank Chun-Yen Hsian for technical assistance in tissue preparation from pathologic paraffin blocks and Dr Hui-Chen Lin for advice in statistic analyses. We also thank Dr Hsin-Chen Lee and Shi-Bei Wu for the analysis of D310 mutations and copy number of mtDNA in tissues from patients with ESCC. Finally, the support of the laser microdissection facility from the Division of Experimental Surgery, Department of Surgery of Taipei Veterans General Hospital, is also acknowledged. 


\section{References}

1. Wang LS, Chow KC, Chi KH, Liu CC, Li WY, Chiu JH, et al. Prognosis of esophageal squamous cell carcinoma: analysis of clinicopathological and biological factors. Am J Gastroenterol. 1999;94:1933-40.

2. Hsu CP, Chen CY, Hsia JY, Shai SE. Prediction of prognosis by the extent of lymph node involvement in squamous cell carcinoma of the thoracic esophagus. Eur J Cardiothorac Surg. 2001;19:10-3.

3. Lin CS, Chang SC, Wei YH, Chou TY, Wu YC, Lin HC, et al. Prognostic variables in thoracic esophageal squamous cell carcinoma. Ann Thorac Surg. 2009;87:1056-65.

4. Lightowlers RN, Chinnery PF, Turnbull DM, Howell N. Mammalian mitochondrial genetics: heredity, heteroplasmy and disease. Trends Genet. 1997;13:450-5.

5. Lee HC, Wei YH. Oxidative stress, mitochondrial DNA mutation, and apoptosis in aging. Exp Biol Med (Maywood). 2007;232:592-606.

6. Wallace DC. A mitochondrial paradigm of metabolic and degenerative diseases, aging, and cancer: a dawn for evolutionary medicine. Annu Rev Genet. 2005;39:359-407.

7. Moraes CT. What regulates mitochondrial DNA copy number in animal cells? Trends Genet. 2001;17:199-205.

8. Mambo E, Gao X, Cohen Y, Guo Z, Talalay P, Sidransky D. Electrophile and oxidant damage of mitochondrial DNA leading to rapid evolution of homoplasmic mutations. Proc Natl Acad Sci U S A. 2003;100:1838-43.

9. Andrews RM, Kubacka I, Chinnery PF, Lightowlers RN, Turnbull DM, Howell N. Reanalysis and revision of the Cambridge reference sequence for human mitochondrial DNA. Nat Genet. 1999;23:147.

10. Sanchez-Cespedes M, Parrella P, Nomoto S, Cohen D, Xiao Y, Esteller M, et al. Identification of a mononucleotide repeat as a major target for mitochondrial DNA alterations in human tumors. Cancer Res. 2001;61:7015-9.

11. Lee HC, Yin PH, Lin JC, Wu CC, Chen CY, Wu CW, et al. Mitochondrial genome instability and mtDNA depletion in human cancers. Ann NY Acad Sci. 2005;1042: 109-22.

12. Abnet CC, Huppi K, Carrera A, Armistead D, McKenney K, Hu N, et al. Control region mutations and the 'common deletion' are frequent in the mitochondrial DNA of patients with esophageal squamous cell carcinoma. BMC Cancer. 2004;4:30.

13. Kumimoto H, Yamane Y, Nishimoto Y, Fukami H, Shinoda M, Hatooka S, et al. Frequent somatic mutations of mitochondrial DNA in esophageal squamous cell carcinoma. Int J Cancer. 2004;108:228-31.
14. Kim MM, Clinger JD, Masayesva BG, Ha PK, Zahurak ML, Westra WH et al. Mitochondrial DNA quantity increases with histopathologic grade in premalignant and malignant head and neck lesions. Clin Cancer Res. 2004; 10:8512-5.

15. Lee HC, Li SH, Lin JC, Wu CC, Yeh DC, Wei YH. Somatic mutations in the Dloop and decrease in the copy number of mitochondrial DNA in human hepatocellular carcinoma. Mutat Res. 2004;547:71-8.

16. Wu CW, Yin PH, Hung WY, Li AF, Li SH, Chi CW, et al. Mitochondrial DNA mutations and mitochondrial DNA depletion in gastric cancer. Genes Chromosomes Cancer. 2005;44:19-28.

17. Tseng LM, Yin PH, Chi CW, Hsu CY, Wu CW, Lee LM, et al. Mitochondria DNA mutations and mitochondrial DNA depletion in breast cancer. Genes Chromosomes Cancer. 2006;45:629-38.

18. American Joint Committee on Cancer. AJCC Cancer Staging Manual. 6th ed. Philadelphia: Lippincott-Raven; 2002.

19. Bough KJ, Mott DD, Dingledine RJ. Medial perforant path inhibition mediated by mGluR7 is reduced after status epilepticus. J Neurophysiol. 2004;92: 1549-57.

20. Hung WY, Lin JC, Lee LM, Wu CW, Tseng LM, Yin PH, et al. Tandem duplication/triplication correlated with poly-cytosine stretch variation in human mitochondrial DNA D-loop region. Mutagenesis. 2008;23:137-42.

21. Lin CS, Wang LS, Tsai CM, Wei YH. Low copy number and low oxidative damage of mitochondrial DNA are associated with tumor progression in lung cance tissues after neoadjuvant chemotherapy. Interact Cardiovasc Thorac Surg. 2008; 7:954-8.

22. Lievre A, Blons H, Houllier AM, Laccourreye O, Brasnu D, Beaune P, et al. Clinicopathological significance of mitochondrial D-loop mutations in head and neck carcinoma. Br J Cancer. 2006;94:692-7.

23. Suzuki M, Toyooka S, Miyajima K, Iizasa T, Fujisawa T, Bekele NB, et al. Alterations in the mitochondrial displacement loop in lung cancers. Clin Cancer Res. 2003;9:5636-41.

24. Nowell PC. The clonal evolution of tumor cell populations. Science. 1976;194: 23-8.

25. Warburg O. On respiratory impairment in cancer cells. Science. 1956;124 $269-70$ 

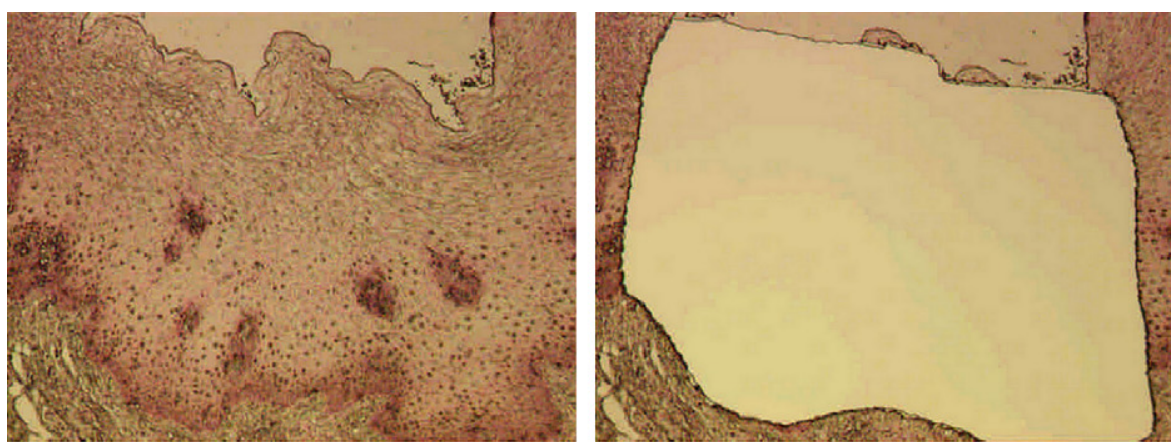

Non-cancerous esophageal mucosa
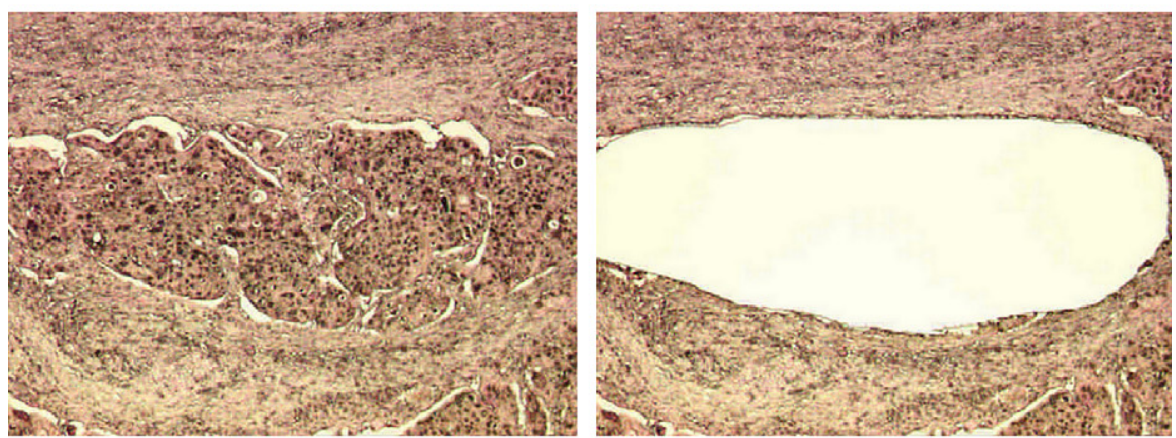

Cancerous ESCC nest
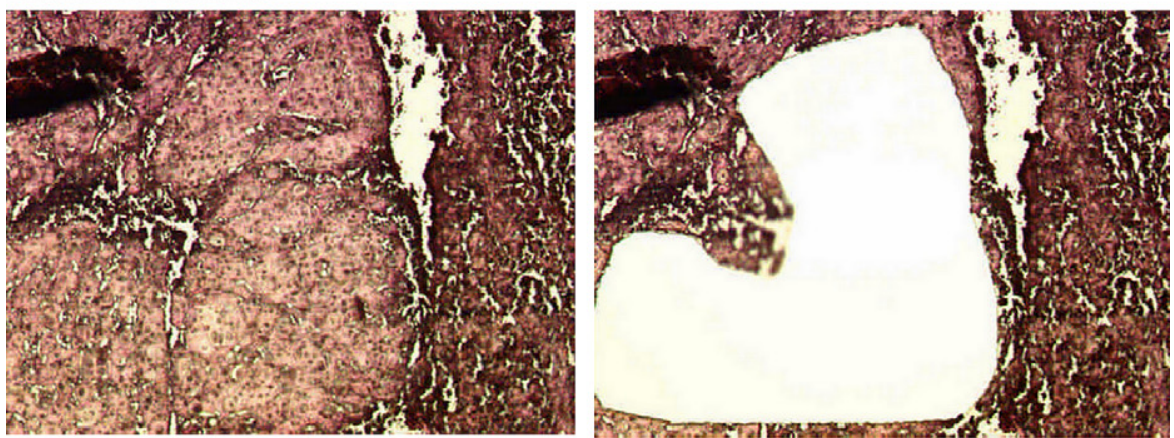

Metastatic lymph node
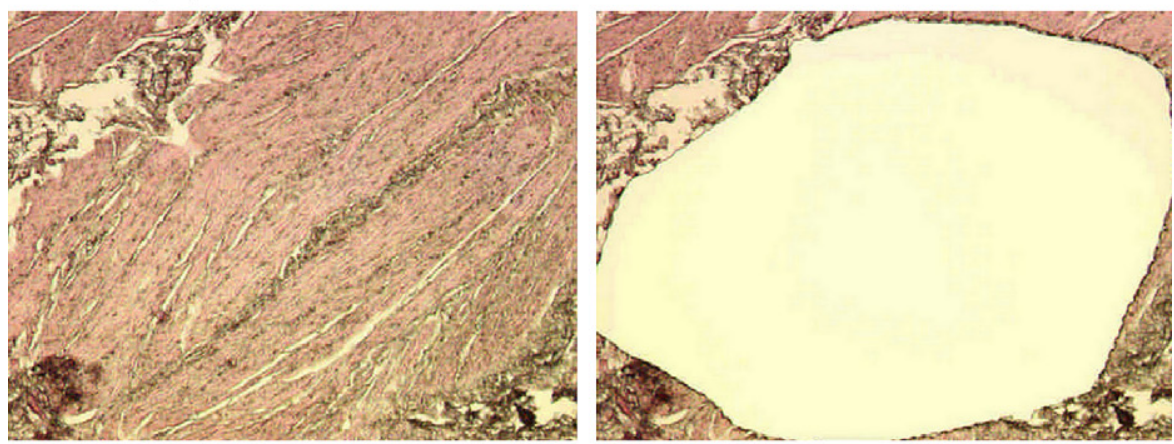

Esophageal muscular tissue

FIGURE E1. Laser microdissection (LMD) adopted for the harvest of samples from noncancerous esophageal mucosa, cancerous ESCC tissues, metastatic lymph nodes, and esophageal muscular tissues of patients with ESCC. First panel: Noncancerous esophageal mucosa before (left) and after (right) LMD. Second panel: Cancerous ESCC tissues before (left) and after (right) LMD. Third panel: Metastatic lymph nodes before (left) and after (right) LMD. Fourth panel: Esophageal muscle tissues before (left) and after (right) LMD. ESCC, Esophageal squamous cell carcinoma. 


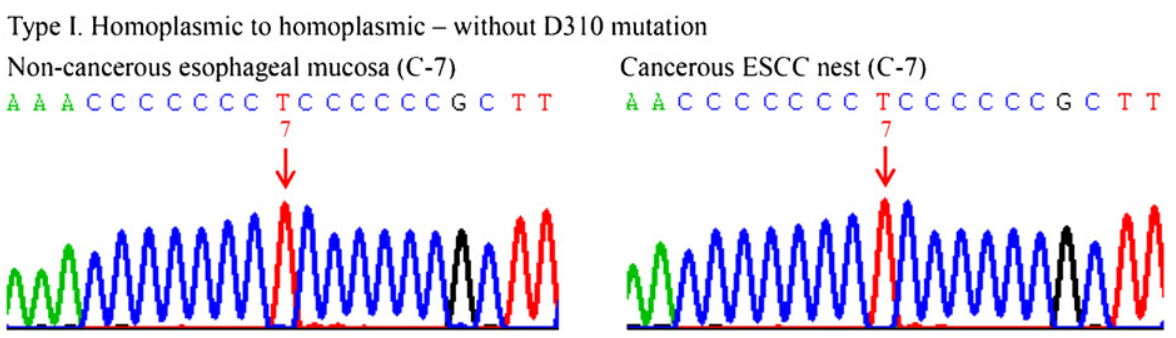

Type II. Homoplasmic to heteroplasmic - with D310 mutation

Non-cancerous esophageal mucosa (C-7)

Cancerous ESCC nest (C-8, C-7, C-9)

A A A C C C C C T C C C C C G T T C.

$\triangle A$ ACCCCCCCC TCCCCCCGC T T T
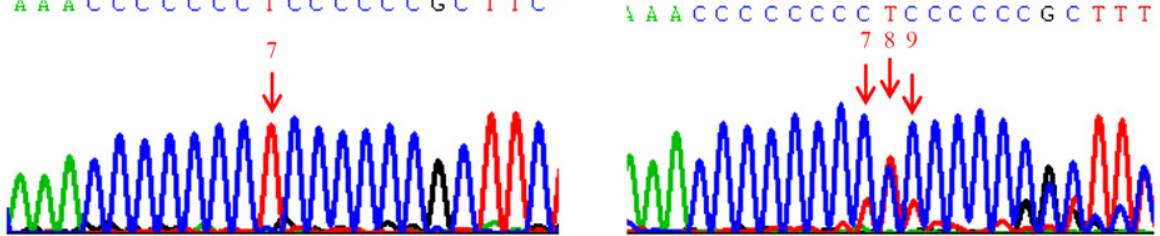

Type III. Heteroplasmic to heteroplasmic - with D310 mutation

Non-cancerous esophageal mucosa (C-8, C-9, C-10)

Cancerous ESCC nest (C-9, C-8, C-10)

$\therefore A A A C C C C C C C C T C C C C C C G C T$

A A C C C C C C TCCCCCCGC T:

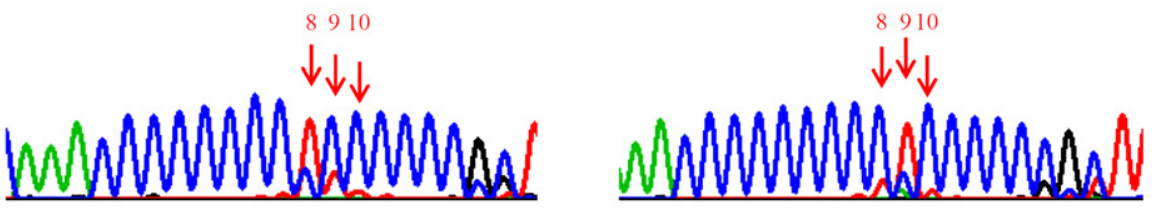

Type IV. Heteroplasmic to homoplasmic - with D310 mutation

Non-cancerous esophageal mucosa (C-8, C-7)

Cancerous ESCC nest (C-8)

A A A C C C C T C C C C C T T

A A ACC C C C T C C C C G T TC
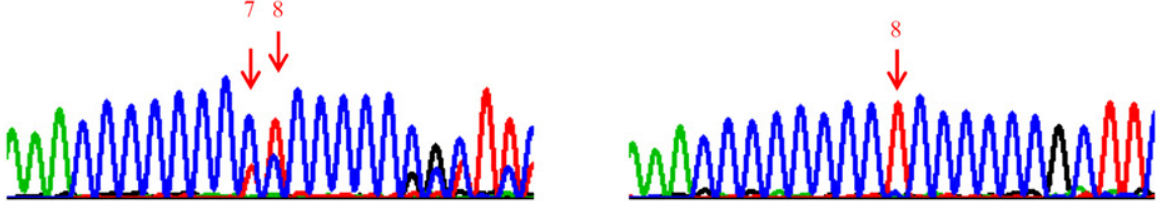

Type V. One Homoplasmic to another homoplasmic - with D310 mutation

Non-cancerous esophageal mucosa (C7)

Cancerous ESCC nest (C8)

A A A C C C C C T C C C C C C T TC T

A A A C C C C C C TCCCCCCGC T T
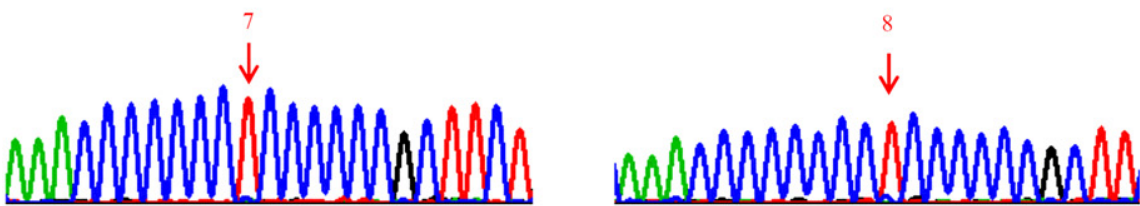

FIGURE E2. Types of somatic D310 alterations of mtDNA between noncancerous esophageal mucosa (left) and cancerous ESCC tissues (right). Arabic number above the red arrow denotes the cytidine number before the indicated thymidine peak, which is shown in red color during D310 sequencing. Type I, homoplasmic to homoplasmic (first row): The example shows homoplasmic C-7 variant to homoplasmic C-7 variant without D310 mutation. Type II, homoplasmic to heteroplasmic (second row): The example shows homoplasmic C-7 variant to heteroplasmic C-8, C-7, C-9 variants with D310 mutation. Type III, heteroplasmic to heteroplasmic (third row): The example shows heteroplasmic C-8, C-9, C10 variants to heteroplasmic C-9, C-8, C10 variants with proportional change of the D310 variants with D310 mutation. Type IV, heteroplasmic to homoplasmic (fourth row): The example shows heteroplasmic C-8, C-7 variants to homoplasmic C-8 variant with D310 mutation. Type V, homoplasmic to homoplasmic with variant shift (fifth row): The example shows homoplasmic C-7 to homoplasmic C-8 with D310 mutation. ESCC, Esophageal squamous cell carcinoma. 
TABLE E1. Summary of the D310 variants between the paired noncancerous esophageal mucosa and the cancerous esophageal squamous cell carcinoma nests in 72 patients with esophageal squamous cell carcinoma

\begin{tabular}{|c|c|c|c|c|c|c|c|c|c|}
\hline \multirow[b]{2}{*}{$\begin{array}{c}\text { Somatic } \\
\text { D310 mutation } \\
\end{array}$} & \multirow[b]{2}{*}{$\begin{array}{c}\text { Types of } \\
\text { D310 alteration }\end{array}$} & \multirow[b]{2}{*}{ Patient } & \multicolumn{3}{|c|}{ Noncancerous esophageal mucosa } & \multicolumn{3}{|c|}{ Cancerous ESCC nests } & \multirow[b]{2}{*}{ Relationship } \\
\hline & & & $\begin{array}{c}\text { D310* } \\
\text { variants }\end{array}$ & Major & Pattern & $\begin{array}{c}\text { D310* } \\
\text { variants }\end{array}$ & Major & Pattern & \\
\hline \multirow[t]{16}{*}{ No $(n=16)$} & \multirow{16}{*}{$\begin{array}{l}\text { I (homoplasmic } \\
\text { to homoplasmic) }\end{array}$} & A06 & 7 & 7 & Homoplasmy & 7 & 7 & Homoplasmy & Fully related \\
\hline & & A10 & 7 & 7 & Homoplasmy & 7 & 7 & Homoplasmy & Fully related \\
\hline & & A12 & 7 & 7 & Homoplasmy & 7 & 7 & Homoplasmy & Fully related \\
\hline & & B03 & 7 & 7 & Homoplasmy & 7 & 7 & Homoplasmy & Fully related \\
\hline & & B09 & 7 & 7 & Homoplasmy & 7 & 7 & Homoplasmy & Fully related \\
\hline & & $\mathrm{C} 08$ & 7 & 7 & Homoplasmy & 7 & 7 & Homoplasmy & Fully related \\
\hline & & $\mathrm{C} 10$ & 7 & 7 & Homoplasmy & 7 & 7 & Homoplasmy & Fully related \\
\hline & & D02 & 7 & 7 & Homoplasmy & 7 & 7 & Homoplasmy & Fully related \\
\hline & & D07 & 7 & 7 & Homoplasmy & 7 & 7 & Homoplasmy & Fully related \\
\hline & & D09 & 7 & 7 & Homoplasmy & 7 & 7 & Homoplasmy & Fully related \\
\hline & & E06 & 7 & 7 & Homoplasmy & 7 & 7 & Homoplasmy & Fully related \\
\hline & & E07 & 7 & 7 & Homoplasmy & 7 & 7 & Homoplasmy & Fully related \\
\hline & & E10 & 7 & 7 & Homoplasmy & 7 & 7 & Homoplasmy & Fully related \\
\hline & & F06 & 7 & 7 & Homoplasmy & 7 & 7 & Homoplasmy & Fully related \\
\hline & & F07 & 7 & 7 & Homoplasmy & 7 & 7 & Homoplasmy & Fully related \\
\hline & & F10 & 7 & 7 & Homoplasmy & 7 & 7 & Homoplasmy & Fully related \\
\hline \multirow[t]{8}{*}{ Yes $(\mathrm{n}=8)$} & \multirow{8}{*}{$\begin{array}{l}\text { II (homoplasmic } \\
\text { to heteroplasmic) }\end{array}$} & $\mathrm{A} 03$ & 7 & 7 & Homoplasmy & 7,8 & 7 & Heteroplasmy & Partially related \\
\hline & & $\mathrm{A} 07$ & 7 & 7 & Homoplasmy & 7,9 & 7 & Heteroplasmy & Partially related \\
\hline & & B10 & 8 & 8 & Homoplasmy & 8,9 & 8 & Heteroplasmy & Partially related \\
\hline & & $\mathrm{C} 06$ & 7 & 7 & Homoplasmy & 7,10 & 7 & Heteroplasmy & Partially related \\
\hline & & E01 & 7 & 7 & Homoplasmy & $7,9,10,11$ & 7 & Heteroplasmy & Partially related \\
\hline & & E02 & 7 & 7 & Homoplasmy & $7,8,6$ & 7 & Heteroplasmy & Partially related \\
\hline & & F11 & 7 & 7 & Homoplasmy & $8,7,9$ & 8 & Heteroplasmy & Partially related \\
\hline & & G03 & 8 & 8 & Homoplasmy & 7,8 & 7 & Heteroplasmy & Partially related \\
\hline \multirow[t]{23}{*}{ Yes $(n=23)$} & \multirow{23}{*}{$\begin{array}{l}\text { III (heteroplasmic } \\
\text { to heteroplasmic) }\end{array}$} & A01 & $8,9,10$ & 8 & Heteroplasmy & $9,8,10$ & 9 & Heteroplasmy & Fully related \\
\hline & & A02 & $10,9,11,8$ & 10 & Heteroplasmy & $9,10,8,11$ & 9 & Heteroplasmy & Fully related \\
\hline & & A04 & $9,8,10,11$ & 9 & Heteroplasmy & $9,10,8,11$ & 9 & Heteroplasmy & Fully related \\
\hline & & B01 & 8,9 & 8 & Heteroplasmy & 8,9 & 8 & Heteroplasmy & Fully related \\
\hline & & B04 & 8,9 & 8 & Heteroplasmy & $8,7,6$ & 8 & Heteroplasmy & Partially related \\
\hline & & B06 & $8,9,10,11$ & 8 & Heteroplasmy & $8,9,10$ & 8 & Heteroplasmy & Fully related \\
\hline & & B08 & $9,8,10$ & 9 & Heteroplasmy & 7,8 & 7 & Heteroplasmy & Partially related \\
\hline & & B12 & $7,9,8$ & 7 & Heteroplasmy & $9,7,8$ & 9 & Heteroplasmy & Fully related \\
\hline & & $\mathrm{C} 02$ & 7,8 & 7 & Heteroplasmy & $10,9,8$ & 10 & Heteroplasmy & Partially related \\
\hline & & $\mathrm{C} 04$ & $8,7,9,10$ & 8 & Heteroplasmy & $9,8,7,10$ & 9 & Heteroplasmy & Fully related \\
\hline & & C09 & $9,8,7$ & 9 & Heteroplasmy & 10,9 & 10 & Heteroplasmy & Partially related \\
\hline & & $\mathrm{C} 11$ & 8,9 & 8 & Heteroplasmy & 8,9 & 8 & Heteroplasmy & Fully related \\
\hline & & D05 & 8,9 & 8 & Heteroplasmy & $8,7,6$ & 8 & Heteroplasmy & Partially related \\
\hline & & D06 & 9,8 & 9 & Heteroplasmy & 9,8 & 9 & Heteroplasmy & Fully related \\
\hline & & D08 & $11,10,9$ & 11 & Heteroplasmy & 9,8 & 9 & Heteroplasmy & Partially related \\
\hline & & E04 & $9,7,10,8$ & 9 & Heteroplasmy & $8,9,10$ & 8 & Heteroplasmy & Fully related \\
\hline & & E05 & $8,9,7$ & 8 & Heteroplasmy & $8,9,7$ & 8 & Heteroplasmy & Fully related \\
\hline & & E09 & 9,8 & 9 & Heteroplasmy & 9,8 & 9 & Heteroplasmy & Fully related \\
\hline & & F02 & $8,7,9$ & 8 & Heteroplasmy & 8,9 & 8 & Heteroplasmy & Fully related \\
\hline & & F03 & $8,9,10$ & 8 & Heteroplasmy & 8,9 & 8 & Heteroplasmy & Fully related \\
\hline & & F05 & $9,10,8$ & 9 & Heteroplasmy & 8,9 & 8 & Heteroplasmy & Fully related \\
\hline & & F08 & $8,9,10,7$ & 8 & Heteroplasmy & $9,10,8,7$ & 9 & Heteroplasmy & Fully related \\
\hline & & G02 & 7,8 & 7 & Heteroplasmy & 7,9 & 7 & Heteroplasmy & Partially related \\
\hline
\end{tabular}


TABLE E1. Continued

\begin{tabular}{|c|c|c|c|c|c|c|c|c|c|}
\hline \multirow[b]{2}{*}{$\begin{array}{c}\text { Somatic } \\
\text { D310 mutation }\end{array}$} & \multirow[b]{2}{*}{$\begin{array}{c}\text { Types of } \\
\text { D310 alteration }\end{array}$} & \multirow[b]{2}{*}{ Patient } & \multicolumn{3}{|c|}{ Noncancerous esophageal mucosa } & \multicolumn{3}{|c|}{ Cancerous ESCC nests } & \multirow[b]{2}{*}{ Relationship } \\
\hline & & & $\begin{array}{c}\text { D310* } \\
\text { variants }\end{array}$ & Major & Pattern & $\begin{array}{c}\text { D310* } \\
\text { variants }\end{array}$ & Major & Pattern & \\
\hline \multirow[t]{23}{*}{ Yes $(n=23)$} & \multirow{23}{*}{$\begin{array}{l}\text { IV (heteroplasmic } \\
\text { to homoplasmic) }\end{array}$} & A05 & $8,7,9$ & 8 & Heteroplasmy & 8 & 8 & Homoplasmy & Fully related \\
\hline & & A08 & $8,9,10$ & 8 & Heteroplasmy & 8 & 8 & Homoplasmy & Fully related \\
\hline & & A09 & $8,9,10$ & 8 & Heteroplasmy & 8 & 8 & Homoplasmy & Fully related \\
\hline & & A11 & 10,9 & 10 & Heteroplasmy & 8 & 8 & Homoplasmy & Not related \\
\hline & & B02 & $9,8,10$ & 9 & Heteroplasmy & 8 & 8 & Homoplasmy & Fully related \\
\hline & & B05 & $8,7,9,10$ & 8 & Heteroplasmy & 8 & 8 & Homoplasmy & Fully related \\
\hline & & B07 & $8,9,7$ & 8 & Heteroplasmy & 8 & 8 & Homoplasmy & Fully related \\
\hline & & B11 & $8,10,9$ & 8 & Heteroplasmy & 8 & 8 & Homoplasmy & Fully related \\
\hline & & $\mathrm{C} 01$ & $8,9,10$ & 8 & Heteroplasmy & 8 & 8 & Homoplasmy & Fully related \\
\hline & & $\mathrm{C} 03$ & 7,8 & 7 & Heteroplasmy & 8 & 8 & Homoplasmy & Fully related \\
\hline & & $\mathrm{C} 05$ & 8,9 & 8 & Heteroplasmy & 8 & 8 & Homoplasmy & Fully related \\
\hline & & $\mathrm{C} 07$ & $9,8,10$ & 9 & Heteroplasmy & 8 & 8 & Homoplasmy & Fully related \\
\hline & & $\mathrm{C} 12$ & $8,9,10$ & 8 & Heteroplasmy & 8 & 8 & Homoplasmy & Fully related \\
\hline & & D01 & $8,9,7$ & 8 & Heteroplasmy & 7 & 7 & Homoplasmy & Fully related \\
\hline & & D03 & 9,8 & 9 & Heteroplasmy & 8 & 8 & Homoplasmy & Fully related \\
\hline & & D04 & $8,10,9$ & 8 & Heteroplasmy & 8 & 8 & Homoplasmy & Fully related \\
\hline & & D10 & 8,7 & 8 & Heteroplasmy & 8 & 8 & Homoplasmy & Fully related \\
\hline & & D12 & 8,9 & 8 & Heteroplasmy & 8 & 8 & Homoplasmy & Fully related \\
\hline & & E08 & 7,8 & 7 & Heteroplasmy & 7 & 7 & Homoplasmy & Fully related \\
\hline & & E11 & 10,9 & 10 & Heteroplasmy & 7 & 7 & Homoplasmy & Not related \\
\hline & & F04 & $9,8,10,11$ & 9 & Heteroplasmy & 4 & 4 & Homoplasmy & Not related \\
\hline & & F09 & 8,7 & 8 & Heteroplasmy & 8 & 8 & Homoplasmy & Fully related \\
\hline & & G04 & $8,9,7$ & 8 & Heteroplasmy & 8 & 8 & Homoplasmy & Fully related \\
\hline \multirow[t]{2}{*}{ Yes $(n=2)$} & \multirow{2}{*}{$\begin{array}{l}\mathrm{V} \text { (A homoplasmic } \\
\text { to B homoplasmic) }\end{array}$} & E12 & 7 & 7 & Homoplasmy & 8 & 8 & Homoplasmy & Not related \\
\hline & & G01 & 7 & 7 & Homoplasmy & 8 & 8 & Homoplasmy & Not related \\
\hline
\end{tabular}

\footnotetext{
*The cytidine numbers of D310 variants are listed in order according to the detected sequencing peaks.
} 